\title{
The Casualization of Black Female Labour in South Africa
}

\section{TI Fényes and $\mathbf{P}$ Lalthapersad}

Department of Economics, Vista University, Mamelodi and East Rand

\section{ABSTRACT}

Black women workers in South Africa are highly marginalized in that their work has been undervalued and underpaid due to disadvantage and discrimination. They were severely curtailed by legislation that aimed to keep them away from urban areas and the formal job market. This paper reports the results of an empirical study of the work done by black women in the manufacturing and retail industries. The purpose of the study was to determine the kind of work black women do and the nature of the job processes. The article examines the main findings of the study.

JEL J 16

\section{INTRODUCTION}

Gender oppression occurs in all societies and its form rests on the socio-political forces located in the society. In South Africa, women's oppression was mainly shaped by two socio-political factors:

- the ideology of apartheid and racial exclusivity which fostered white supremacy and black inferiority; and

- the development of the capitalist sector (Gwagwa, 1989).

Thus in South Africa, the oppression of black women was tightly bound to national oppression. The state viewed black women as the most inferior of all racial groups and capital regarded them as the cheapest source of labour. They had often no legal rights, could not own property, were given the least skilled jobs and were forced to eke out an existence in the tribal homelands. Poor access to education and training, lack of housing, the skewed provision of fringe benefits and the wider socio-political dynamics enmeshed to lock black women into a web of hardship, poverty, control and marginality. Black women were entrapped in a state of triple bondage in that they were oppressed as a race, a class and as women. 
Black women endured the cumulative burden of low wages for themselves and their spouses, male migration, live-in domestic jobs, poverty, customary law, traditionalism and state regulation. The state exerted rigid control over the lives of black families. Laws governed the physical movement of black people, access to the cities, the right to housing and above all access to the job market (Berger, 1992: 13). Once in the urban areas, black women had to contend with the threat of deportation back to the tribal homelands and arrest if they lacked legal documentation. The pass laws specifically denied black women access to the urban areas and the job market, a factor that polarized the position of women of different races.

Black women could not refuse jobs seeing that they were confronted with a limited range of work. Their dire economic circumstances meant that they could not afford a break in their working lives due to childbearing or marriage.

The experience of black women in South Africa is unique compared to that of working women of other racial groups within the country and of women in other countries. Whilst these women could rely on male earnings and were privileged in that they could retreat to the household if so desired, black women had little choice as they were household heads with families to support.

The geographic distribution of black labour exuded a sexual dimension, that is, black men in the town and black women in the rural areas. Of all groups in South Africa, black women were the last ones to be proletarianized (Bozzoli, 1983: 150). When women entered the urban areas, they had to contend with low paying and unskilled work.

The racial stratification of society underpinned occupational mobility in the job market. The feminization of occupations assumed a racial character. This was especially evident in the manufacturing sector where white women used the entry of black women into the industry to segregate jobs racially. White women moved into the cleaner, lighter, clerical and administrative positions and left black women to tackle the heavy menial jobs in factories (Walker, 1990: 163). Thus black women created occupational mobility for white women. Racism rigidified the occupational structure with white women occupying the skilled jobs and black women doing menial and unskilled work.

Black women dominate the essentially female-oriented economic sectors such as sales and service work where they are employed as cleaners, tealadies, messengers and cooks (Kraak, 1993: 84).

In 1996 the occupational structure in SA showed the following trends:

- black women comprise a minor part (26\%) of the managerial and 
administrative staff;

- black women dominate the service and farming occupations (84\% and $81 \%$ respectively);

- over $40 \%$ of the occupations of black women are classified as "unspecified"; and:

- black women comprise a small portion of artisans and apprentices (Statistic South Africa, 1998).

\section{THE SOUTH AFRICAN LABOUR MARKET}

Segmentation and stratification of the labour market has splintered workers into distinct groups, each with its unique characteristics. The South African labour market is mainly split along racial and gender lines. Black women comprise a "peripheral" rather than a "core" workforce in the sense that they perform mostly unskilled, menial jobs that are secondary or subsidiary to the production process. Black women, still are, disadvantaged in terms of employment, work status, occupational and sectoral segregation, income levels and lack of worker representation (Standing et al. 1996: 389-414).

Black women dominate the segments of the labour market where income, training, promotion prospects and working conditions are poor. In addition, they are afforded little protection against dangerous and exploitative conditions. There are very few black women in management, technical and supervisory positions.

Black women are also more likely to be employed in part-time and casual jobs. They are prone to employment insecurity (likely to be arbitrarily dismissed due to the nature of their employment); job insecurity (denied the means to develop a career); work insecurity (likely to work in dangerous and unsafe conditions) and income insecurity (eam extremely low wages and have little chance of improving their income levels) (Standing et al. 1996: 396-7). The nature of jobs that black women do is prone to downsizing and redundancies.

\section{THE EMPIRICAL STUDY}

The survey on which this paper is based, was conducted in 1998 and formed part of the research for a doctoral thesis. The lack of suitable and recent information on labour force participation in the South African labour market made such an investigation both urgent and worthwhile. The authors themselves designed the survey questionnaire. 
The study thus took the form of a questionnaire survey in the manufacturing and retail industries'. Whilst manufacturing falls under the secondary sector, retail trade is part of the service or tertiary sector. The aim of the survey was to determine the following:

- the jobs black women perform;

- the nature of the work itself;

- the skills levels of black women;

- the extent of flexibility in terms of part-time, full-time, shift and overtime work; and

- the possibility of sustaining injuries in the course of work.

The questionnaire was exploratory in nature, designed to capture the type of information that census data does not reflect, namely, the conditions and nature of work itself. Census data are inadequate in that occupational categories are so broad that many different jobs are compressed together. This precludes any information on the different incomes and working conditions that the jobs entail.

The questionnaire looked at employment practices, that is, the issue of flexibility, and the use of non-regular employment was also addressed. Parttime work is a form of numerical or external flexibility. This section aimed to verify the growing trend favouring the use of non-regular employment rather than permanent full-time workers.

The type of work that black women do formed a large proportion of the questionnaire. Under type of work, three aspects were touched on :

- the distribution of women according to departments or sections at a factory level;

- the functional tasks of black women; and

- the main products and materials handled by black women.

Analysing the distribution of black women according to departments or sections at a factory or shop level, is reflective of the demographics of the workplace. Regarding the tasks that black women may undertake, a comprehensive list of thirty-three possible tasks was provided. Although many of the tasks overlapped, it was hoped that the response would provide greater clarity on the nature of the work performed by black women.

The list of materials and products complies with the standard classification used by Statistics South Africa (SSA). The type of materials and products handled can serve as an indicator as to whether certain industries are inclined to hire a certain gender. 
The questionnaire also dealt with the working conditions and hazards that black women encounter, that is, whether they are exposed to grease, dust or dangerous fumes. Such information exposes the nature of work black women do, whether they have to contend with dangerous, exploitative working conditions, the health and safety of workers and their place in the job hierarchy.

The questionnaire also looked at the likelihood of sustaining injury in the execution of one's job. Such information can be used to gauge the potential riskiness of jobs performed by black women. Another aspect of the questionnaire dealt with the physical effort required by the job. Specifically, the following matters were examined:

- the postures that black women adopt in performing their jobs;

- the kind of weight black women pick up or handle;

- the importance of special skills for job performance; and

- whether the work that black women do requires ordinary, definite, considerable or great physical strength.

A further aspect of the questionnaire dealt with the skills and educational levels of black women. Four broad categories defined by SSA were provided, and firms were asked to categorize workers according to these definitions. The skills and educational levels of workers are crucial in segmenting the labour market and determining the workers' place in the hierarchy.

\section{SURVEY METHOD}

Two industries, namely, manufacturing and retailing were chosen because they have historically employed large numbers of black women. Only the Gauteng region was considered. The industrial register at the Bureau of Market Research (BMR) of the University of South Africa served as basis for choosing the sample. In the manufacturing industry, only firms with a staff complement of more than a hundred workers were considered. In retailing, only firms with over thirty workers were included.

Firms were randomly selected and a total of 300 questionnaires were sent by mail. A total of 265 questionnaires were returned (139 from manufacturing and 126 from retailing firms). This gives a total response rate of $88 \%$.

The categorical nature of biographic and organizational questions made it appropriate to work with frequency distributions, and in the cross tabulation of two variables to calculate the Chi-square statistic as a test of the null hypothesis of independence (Hays, 1963: 558-9). 
The questionnaire required the respondent to respond on a 4 or 5 point Likert type scale. Since such questions give information on an interval scale, it is important to calculate mean scores for subgroups. In the present study, the mean scores obtained for different groups were compared using the so-called ttest for differences between means of independent groups (Hays, 1963: 280).

Conventionally, the levels of 0.05 and 0.01 are used as levels of significance performed to control the so-called type-I error rate, that is, to limit the risk of incorrectly rejecting the null hypothesis or concluding a significant result (Hays, 1963: 281). In the social sciences, we are mainly concerned about missing a significant result (type-II error). Winer (1971: 14-15) points out that when both types of errors (type-I and type-II) are equally important, levels such as 0.20 (and possibly 0.30 ) are more appropriate than the conventionally used 0.05 and 0.01 levels.

In this study, it was decided to use statistics mostly on an item level. This resulted in more than 100 tests being performed. In order to achieve reasonable protection against type-I error, the authors decided to use a level of 0.005 for any one particular test. This choice remains arbitrary to a large extent.

Firms in manufacturing were subdivided into two industrial types based on the kind of output they produce, namely light and heavy industries. Light industries are comprised of:

- food, beverages and tobacco products;

- textiles, clothing, leather products and substitutes, footwear; and

- pottery, china, glass products and other non-metallic products.

Heavy industries are comprised of:

- wood and cork products, furniture and fixtures;

- $\quad$ paper and paper products, printing and publishing;

- industrial chemicals, petroleum and coal products, rubber and plastic products;

- iron and steel industries and non-ferrous basic metal industries; and

- fabricated metal products, machinery, motor vehicles and transport equipment.

\section{SURVEY FINDINGS}

In this section, the main findings of the empirical study and its implications for the future utilization of black female labour are discussed. 


\section{Classification of job criteria}

Question 8 in the questionnaire (see Endnote) required firms to rate the extent to which they utilize the criteria in Table 1 to classify jobs.

Table 1 Criteria used to classify jobs in manufacturing and retail industries

\begin{tabular}{|c|c|c|c|c|c|}
\hline \multirow{2}{*}{$\begin{array}{l}\text { Classification } \\
\text { criteria }\end{array}$} & \multicolumn{2}{|c|}{ Manufacturing } & \multicolumn{2}{|c|}{ Retail } & \multirow{2}{*}{$\begin{array}{c}\text { P- } \\
\text { value }\end{array}$} \\
\hline & Mean & Std & Mean & Std & \\
\hline Education & 3.36 & 0.967 & 3.07 & 0.964 & 0.129 \\
\hline Mental effort & 3.47 & 0.885 & 3.30 & 0.981 & 0.145 \\
\hline Skills & 3.69 & 0.905 & 3.40 & 1.085 & 0.017 \\
\hline Physical effort & 2.80 & 0.953 & 2.81 & 1.080 & 0.917 \\
\hline Responsibility & 3.67 & 0.889 & 3.35 & 1.076 & 0.010 \\
\hline Working conditions & 3.48 & 0.947 & 3.23 & 1.005 & 0.038 \\
\hline
\end{tabular}

According to the criteria used to classify jobs, it appears that all five factors except "physical effort" are deemed important (mean score greater than 3) in classifying jobs (Table 1). However, "skills" (mean score of 3.67) and "responsibility" (mean score of 3.69) are the most relevant factors. Firms consider "physical effor" least relevant, possibly because it is not seen as warranting special attention and is accepted as a given.

\section{Overtime, full-time and shift work}

Questions 1, 2, 16, 17 and 18 called for information on the use of full-time workers, part-time workers, shift work and overtime work. Figure 1 shows the results obtained. 
Figure 1 Overtime, shift and full-time work in the retailing and manufacturing industries

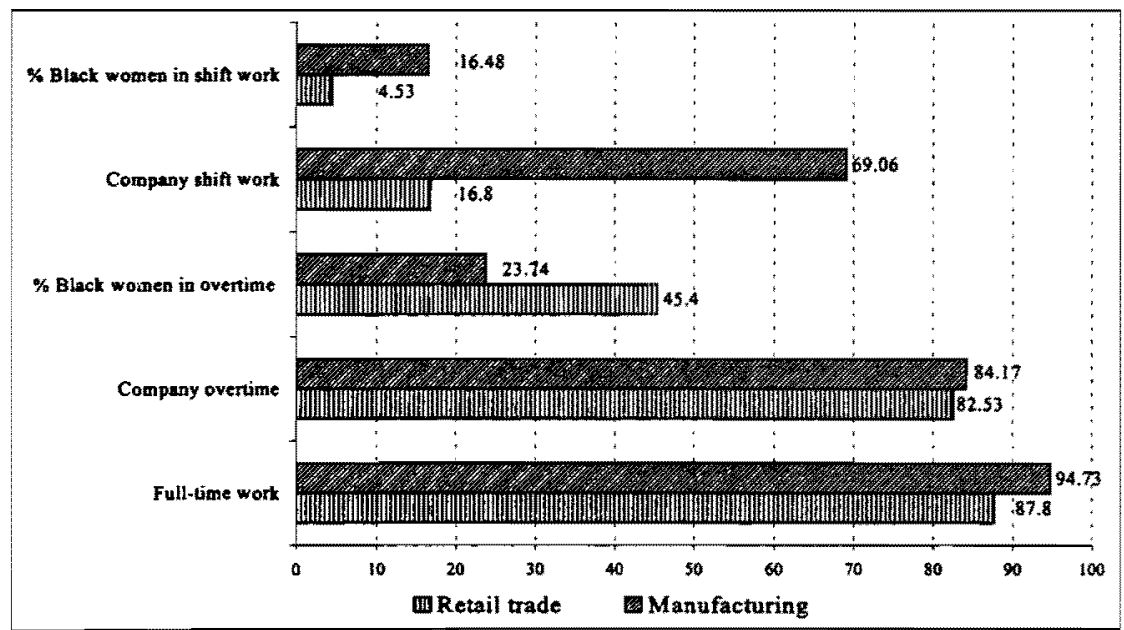

For all firms, $98 \%$ of the workforce were employed on a full-time basis, respectively $87.8 \%$ in retail trade and $94.7 \%$ in manufacturing. Only $12.2 \%$ of workers in retail trade and $5.35 \%$ in manufacturing were part-time workers. It is apparent that part-time work is not very widespread, a deviation from the international trend and an indication of low labour market flexibility. However, the greater occurrence of part-time work in retailing, is due to the fact that the service sector tends to employ large numbers of women in jobs that are labourintensive in nature.

Both industries make substantial use of overtime, that is, over $80 \%$. However, for all firms, only $34 \%$ of black women workers were involved in overtime work. The number of black women involved in overtime is higher in retail trade $(45.4 \%)$ compared to manufacturing (23.7\%). Higher overtime rates in retailing could be attributed to the fact that many black women are employed as salesworkers and work extended hours over weekends.

Shift work existed only at $44.5 \%$ of all firms and only $11 \%$ of black women employees worked shifts. Overall, the use of shift work is very low in the retail sector $(16.8 \%)$ but substantially higher in the manufacturing industry $(69 \%)$. This could be due to the production processes used in manufacturing. 
The survey also showed that black women did less shift work compared to the general workforce (namely, $4.5 \%$ in retailing and $16.4 \%$ in manufacturing). A possible reason for this is that black women are not so much doing technical jobs but jobs that are peripheral to the production process, like packing.

\section{Potential risk of injury}

Question 3 of the questionnaire asked firms to assess the likelihood of black women sustaining certain injuries in their job environment. The results are shown in Figure 2.

Figure 2 Risk of injuries to black women in retail and manufacturing industries

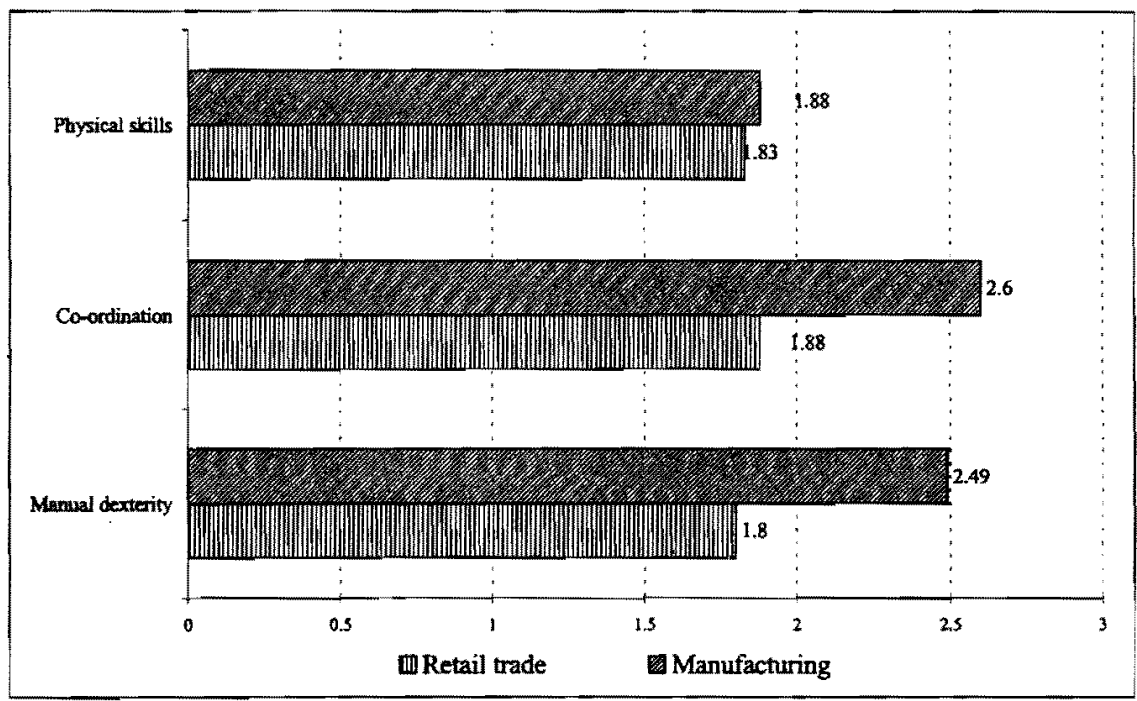

The retail and manufacturing industries are quite similar in terms of exposure to injury. "Possibility of accidents" occurring is lower in retail trade $(69.8 \%)$ compared to manufacturing (75.5\%). "Bums" have the lowest occurrence in both retailing $(20.5 \%)$ and manufacturing $(51.6 \%)$ but are relatively higher in manufacturing. "Bruises" are the second highest category of injury likely to occur, namely, $79.2 \%$ in retail trade and $73.5 \%$ in manufacturing. "Cuts" are the most common injury, that is, $84 \%$ in retail trade and $82.5 \%$ in manufacturing industries. 
These statistics indicate that the work environment of black women is not particularly safe as the likelihood of sustaining injury exists to quite a substantial extent.

In comparing heavy and light industries, it is noticeable that the occurrence of injuries such as accidents, cuts, burns and bruises is higher in heavy industries. This is because jobs in heavy industries are more physically demanding. Also the type of output differs between the two industries.

\section{Exposure to hazards}

Question 14 of the questionnaire requested firms to rate the extent to which black women are exposed to certain hazards in the work environment. The results are shown in Table 2.

Table 2 Exposure to hazards in manufacturing and retail industries

\begin{tabular}{|l|c|c|c|c|c|}
\hline \multirow{2}{*}{ Type of hazard } & \multicolumn{2}{|c|}{ Manufacturing } & \multicolumn{2}{c|}{ Retail Trade } & \multirow{2}{*}{ P-value } \\
\cline { 2 - 5 } & Mean & Std & Mean & Std & \\
\hline Explosives & 1.06 & 0.344 & 1.03 & 0.250 & 0.3709 \\
Height & 1.09 & 0.338 & 1.64 & 0.874 & 0.0001 \\
Fire & 1.40 & 0.940 & 1.93 & 1.078 & 0.0001 \\
Radiation & 1.02 & 0.168 & 1.00 & 0 & 0.0451 \\
Atmosphere & 1.37 & 0.827 & 1.09 & 0.344 & 0.0004 \\
Chemicals & 1.33 & 0.736 & 1.07 & 0.325 & 0.0003 \\
Electrical & 1.76 & 0.921 & 1.38 & 0.534 & 0.0001 \\
Mechanical & 2.00 & 1.073 & 1.14 & 0.394 & 0.0001 \\
Self safety & 3.17 & 1.398 & 2.07 & 1.146 & 0.0001 \\
Other safety & 2.74 & 1.315 & 1.81 & 0.906 & 0.0001 \\
\hline
\end{tabular}

Black women employees were rated as being exposed to hazards "to a fair extent". A pertinent result of the survey is that black women in both manufacturing and retail industries are "responsible for their own safety", a factor that is significantly more important in manufacturing industry. Also in manufacturing industry black women are "responsible for the safety of others". Generally, it appears that black women in the manufacturing industries are more exposed to hazards than in the retail trade, with the exceptions of "fire" (P value of 0.0001 ) and "height" ( $P$ value of 0.0001 ) where the reverse is true. "Mechanical" and "electrical" hazards (both with a $P$ value of 0.0001 ) are substantially bigger in manufacturing. 
Relativeiy greater exposure to hazards in the manufacturing industry is consistent with mechanized job processes. It can be deduced that the work environment of black women does not appear to be particularly dangerous in terms of health risks.

\section{Exposure to harmful conditions}

Question 9 of the questionnaire requested firms to rate the extent to which black women were exposed to various harmful conditions in industry. Table 3 shows the scores obtained.

Table 3 Exposure to harmful conditions in manufacturing and retail industries

\begin{tabular}{|l|c|c|c|c|c|}
\hline \multirow{2}{*}{ Conditions } & \multicolumn{2}{|c|}{ Manufacturing } & \multicolumn{2}{c|}{ Retail trade } & \multirow{2}{*}{ P-value } \\
\cline { 2 - 5 } & Mean & Std & Mean & Std & \\
\hline Grease & 1.58 & 0.784 & 1.11 & 0.342 & 0.000 \\
Coolants & 1.72 & 0.891 & 1.10 & 0.306 & 0.000 \\
General noise & 2.35 & 1.119 & 1.49 & 0.745 & 0.000 \\
Fumes & 1.47 & 0.735 & 1.09 & 0.294 & 0.000 \\
Dust & 2.14 & 0.996 & 1.93 & 1.063 & 0.104 \\
Dirt & 2.18 & 0.990 & 1.87 & 0.937 & 0.010 \\
Asbestos & 1.05 & 0.277 & 1.07 & 0.271 & 0.392 \\
\hline
\end{tabular}

Black women are relatively unexposed to harmful conditions or irritants in the work environment. Exposure to "asbestos" is non-existent (mean scale score close to 1) in both the retail and manufacturing industries. A relatively higher amount of exposure to "noise" (mean score of 2.35), "dirt" (mean score of 2.18) and "dust" (mean score of 2.14) is experienced in manufacturing industries. This could be due to three factors:

- the type of materials and goods handled;

- the size of the enterprise; and

- the level of technology.

In the retail industry, only "dust" (1.93) and "dirt" (1.87) are relatively important negative factors in the activity of packing.

\section{Postures of work and physical demands}

Question 10 of the questionnaire requested the respondent to rate the extent to which black women adopt certain postures when performing their jobs. Table 4 displays the scores obtained. 
Table 4 Postures of work in manufacturing and retail industries

\begin{tabular}{|l|c|c|c|c|c|}
\hline \multirow{2}{*}{ Posture } & \multicolumn{2}{|c|}{ Manufacturing } & \multicolumn{2}{c|}{ Retail trade } & \multirow{2}{*}{ P-value } \\
\cline { 2 - 5 } & Mean & Std & Mean & Std & \\
\hline Climbing & 1.46 & 0.911 & 1.50 & 0.766 & 0.701 \\
Crawling & 1.03 & 0.223 & 1.00 & 0.091 & 0.180 \\
Sitting & 3.14 & 1.540 & 1.84 & 1.248 & 0.000 \\
Walking & 2.50 & 1.175 & 3.32 & 1.441 & 0.000 \\
Standing & 2.87 & 1.554 & 3.92 & 1.293 & 0.000 \\
Bending & 1.52 & 0.872 & 1.83 & 1.052 & 0.012 \\
Crouching & 1.24 & 0.626 & 1.35 & 0.558 & 0.128 \\
Kneeling & 1.11 & 0.472 & 1.21 & 0.576 & 0.134 \\
Stooping & 1.27 & 0.651 & 1.28 & 0.645 & 0.915 \\
\hline
\end{tabular}

Regarding the posture that black women adopt in executing their jobs, it is apparent that none of the physical positions are especially typical of black women workers. The exceptions are "standing" and "walking" in the retail trade with a mean score of 3.92 and 3.32 respectively or ("quite a bit") and "sitting" in the manufacturing industries (mean score of 3.14). These postures are consonant with saleswork, packing and operating light machinery. The "crawling" position is especially uncharacteristic (mean scale score close to 1) in both the retail and manufacturing industries.

Another aspect impinging on the physical demands on black women entailed determining the extent to which their jobs involved physical lifting. The majority of firms (62\%) reported that black women did perform jobs that involved physical lifting. Furthermore, $51.3 \%$ of firms indicated that there were physical demands in the work environment of black women. Jobs involving physical lifting are more prevalent in the retail industry $(69.3 \%)$ compared to manufacturing $(55 \%)$. Black women are also more involved in jobs requiring physical lifting in the light $(65.1 \%)$ than heavy industries $(55 \%)$. This might be due to the large amount of packing that occurs in these industries.

For all firms, the average weight that black women lift in their jobs is $9.5 \mathrm{~kg}$. It appears that the average weight lifted is heavier in retailing $(10.7 \mathrm{~kg})$ than in manufacturing $(8.5 \mathrm{~kg})$. Likewise, the average weight lifted is heavier in light compared to heavy industries (14.8kg and $8 \mathrm{~kg}$ respectively). It is probable that in retailing and light industries, black women are responsible for a wide range of related tasks (like packing and arranging goods) apart from their specific job description. 


\section{Functional tasks}

Question 11 of the questionnaire requested the respondent to rate the extent to which the list of functional tasks in Table 5 describes the work of black women.

Table 5 Functional tasks of black women in manufacturing and retail industries

\begin{tabular}{|l|c|c|c|c|c|}
\hline \multicolumn{1}{|c|}{ Functional tasks } & \multicolumn{2}{|c|}{ Manufacturing } & \multicolumn{2}{c|}{ Retail trade } & P-value \\
\cline { 2 - 5 } & Mean & Std & Mean & Std & \\
\hline Packing & 2.97 & 1.609 & 3.69 & 1.341 & 0.0001 \\
Material handler & 2.94 & 1.640 & 2.41 & 1.492 & 0.0064 \\
Machine handler & 2.46 & 1.552 & 1.15 & 0.620 & 0.0001 \\
Stacking & 2.10 & 1.519 & 1.07 & 0.348 & 0.0001 \\
Placing things on & 2.00 & 1.454 & 1.12 & 0.551 & 0.0001 \\
conveyor belt & & & & & \\
Counting & 1.94 & 1.402 & 1.09 & 0.463 & 0.0001 \\
Doing things & 2.00 & 1.496 & 1.09 & 0.445 & 0.0001 \\
Machine operator & 2.44 & 1.629 & 1.28 & 0.847 & 0.0001 \\
Machine minder/ & 2.31 & 1.493 & 1.11 & 0.430 & 0.0001 \\
watching & & & & & \\
General operator & 2.51 & 1.571 & 1.29 & 0.709 & 0.0001 \\
Production worker & 2.81 & 1.679 & 1.23 & 0.801 & 0.0001 \\
Cleaner/tea lady/ & 3.51 & 1.495 & 3.43 & 1.483 & 0.6712 \\
messenger & & & & & \\
Wordprocessor & 2.26 & 1.427 & 1.89 & 1.216 & 0.0238 \\
operator & & & & & \\
Typing & 2.17 & 1.418 & 1.90 & 1.124 & 0.0872 \\
Secretarial & 2.20 & 1.378 & 1.95 & 1.192 & 0.1285 \\
Personnel clerk & 2.29 & 1.415 & 1.92 & 1.271 & 0.0292 \\
Administrative & 2.43 & 1.414 & 2.61 & 1.362 & 0.3137 \\
assistant & & & & & \\
Bookkeeper & 1.76 & 1.002 & 1.58 & 1.075 & 0.1428 \\
Computer operator & 2.20 & 1.345 & 2.44 & 1.472 & 0.1681 \\
Administrative & 2.23 & 1.380 & 2.07 & 1.276 & 0.3112 \\
official & & & & & \\
Telephonist & 2.47 & 1.529 & 2.42 & 1.449 & 0.7819 \\
Sales worker & 1.51 & 0.866 & 4.18 & 1.427 & 0.0001 \\
Technical & 1.49 & 0.958 & 1.34 & 0.826 & 0.1753 \\
Accounts & 2.07 & 1.288 & 1.91 & 1.285 & 0.3381 \\
Ironer & 1.21 & 0.746 & 1.37 & 0.944 & 0.1365 \\
Presser & 1.13 & 0.608 & 1.12 & 0.593 & 0.8747 \\
\hline
\end{tabular}


Table 5 continued

\begin{tabular}{|l|c|c|c|c|c|}
\hline Functional tasks & \multicolumn{2}{|c|}{ Manufacturing } & \multicolumn{2}{c|}{ Retail trade } & P-value \\
\hline & Mean & Std & Mean & Std & \\
\hline Launderer & 1.18 & 0.762 & 1.07 & 0.338 & 0.1009 \\
Dry cleaning & 1.08 & 0.521 & 1.07 & 0.371 & 0.8822 \\
Lift operator & 1.02 & 0.189 & 1.10 & 0.454 & 0.0620 \\
Credit control & 1.83 & 1.253 & 1.91 & 1.436 & 0.6381 \\
Meter reader & 1.03 & 0.223 & 1.15 & 0.480 & 0.0097 \\
Licence inspector & 1.01 & 0.119 & 1.07 & 0.314 & 0.0580 \\
Client canvasser & & & 1.46 & 1.059 & 0.0002 \\
\hline
\end{tabular}

The task of "cleaner, tealady, messenger" is high in both industries with a mean score exceeding 3. In retail industry, most black women are employed as "salesworker" (mean score rlose to 4). Other jobs that are frequently done in retailing industry are those of:

- $\quad$ packing (mean score of 3.69);

- material handler (2.41);

- $\quad$ administrative assisiunt (2.61);

- computer operator (2.44); and

- telephonist (2.42).

In manufacturing industry, the main task of black women are "cleaner, tealady, messenger" with a mean score of 3.51. Other jobs that are commonly done in the manufacturing are those of:

- packing (2.97);

- material handler (2.94);

- $\quad$ production worker (2.81);

- general operator (2.51); and

- telephonist (2.47).

"Packing" is significantly higher in retail industry than manufacturing ( $P$ value of 0.0001 ). The following tasks are especially unrepresentative (mean scale score close to 1) of both the retail and manufacturing industries, namely those of "licence inspector", "lift inspector", "meter reader", "dry cleaner", "launderer", "ironer", "presser" and "client canvasser".

Black women are crowded into certain jobs which ultimately causes low wages. Jobs such as packing, cleaning, serving tea, delivering messages are elementary and unskilled in nature. They are also gender-stereotyped. The type of jobs that black women do belong to that part of the labour market, where jobs entail simple technology, is menial and repetitive in nature. 
The three jobs most frequently done in both light and heavy industries are as follows:

- cleaner, tea lady, messenger with a mean score of 3.54 in heavy and 3.37 in light industries;

- packing with a mean score of 2.71 in heavy and 3.62 in light industries; and

- material handler with a mean score of 2.75 in heavy and 3.20 in light industries.

Jobs such as "machine handler", "machine minder" and "machine operator" are higher in light industries compared to heavy industries. "Packing" is significantly greater in light than in heavy industry.

The greater number of machine handlers and general operators in light compared to heavy industry point to the fact that these industries produce mainly cheap semi and non-durable goods.

In manufacturing, the jobs women do have been deskilled in that they are menial and do not require much responsibility. The ghettoization of jobs is quite evident in that black women mostly do low-paying, auxiliary jobs like packing and cleaning.

The number of black women employed in the technical field is very small. The impression gained is that men dominate technology and technical skills. The small number of black female technical workers could be a consequence of the unequal education system in the past which restricted blacks access to subjects such as science and mathematics (Themba, 1986: 73-97). White-collar jobs such as word "processing", "typing", "secretarial" and "personnel" are higher in the manufacturing industry than in retail trade. These occupations are fairly "new" in that they have only recently been opened to black women.

The number of black women in accounting and bookkeeping is also very low, a consequence of a tainted educational system that offered a limited range of subjects. General administration work, for example, "administrative assistant and official" are quite important in the both industries. They can also be categorized as "new occupations" as they only recently admitted black women.

Jobs such as "stacking or placing things on the conveyor belt" are relatively more frequent in light than in heavy industries. On the other hand, "counting items on the conveyor belt" is higher heavy than in light industries. In relation to other jobs, these jobs are typically unrepresentative, perhaps because conveyor belt technology is utilized to a limited extent in industry. 


\section{Types of job}

Question 15 of the questionnaire requested firms to rate the extent to which black women perform certain types of job. The scores are shown in Table 6 .

Table 6 Type of jobs black women perform in manufacturing and retail industries

\begin{tabular}{|l|l|l|l|l|l|}
\hline \multirow{2}{*}{\multicolumn{1}{c|}{ Job }} & \multicolumn{2}{l|}{ Manufacturing } & \multicolumn{2}{l|}{ Retail trade } & \multirow{2}{*}{ P-value } \\
\cline { 2 - 6 } & Mean & Std & Mean & Std & \\
\hline Sitting in one position & 2.17 & 1.006 & 1.53 & 0.909 & 0.0001 \\
Lengthy operation & 2.20 & 1.204 & 1.24 & 0.643 & 0.0001 \\
Operating long hours & 2.29 & 1.136 & 1.18 & 0.605 & 0.0001 \\
Liaising with people & 1.81 & 0.979 & 3.19 & 1.101 & 0.0001 \\
Sedentary in office & 2.13 & 1.084 & 1.78 & 0.926 & 0.0049 \\
Operate switchboard & 2.05 & 1.152 & 2.38 & 1.192 & 0.0236 \\
Record keeping & 1.86 & 1.015 & 1.99 & 1.103 & 0.3269 \\
Attention to detail & 2.09 & 1.122 & 1.73 & 0.862 & 0.0038 \\
Physical effort & 1.57 & 1.014 & 1.15 & 0.463 & 0.0001 \\
Lifting etc up/down stairs & 1.50 & 1.002 & 1.41 & 0.723 & 0.4073 \\
Bending or stooping & 1.66 & 1.060 & 1.70 & 0.770 & 0.6945 \\
Pushing heavy loads & 1.52 & 1.033 & 1.39 & 0.719 & 0.2214 \\
\hline
\end{tabular}

In this section, a broad summary of job types was provided to ascertain the physical demands of the various jobs. None of the job types are especially performed by black women, that is, having a mean scale score of 2 or "moderately". The exception is possibly "liaising with people" in the retail trade with a mean scale score of just over 3 . Other jobs most frequently done in retailing are "operating the switchboard, keyboard, photocopier or cash register". The "liaison" aspect of jobs is an offshoot of saleswork that is consistent with the finding established earlier that sales and rudimentary administrative jobs are popular in retailing.

In manufacturing, the jobs most frequently performed are as follows:

- $\quad$ operating machines, tools and equipment for long periods of time;

- lengthy operation of machines or tools that require skill and dexterity; and

- $\quad$ sitting in one position.

In manufacturing, work requires more physical effort and is more strenuous. 
Jobs involving "lifting and carrying loads up and down stairs", "bending and stooping" and "pushing heavy loads" are relatively insignificant in both retail trade and manufacturing.

In heavy industries, the jobs most frequently done are:

- $\quad$ operating machines, tools and equipment for long periods;

- paying attention to detail, functional operation and standing for long periods;

- liaising with people; and

- lengthy operation of machines or tools that require skill and dexterity.

In light industries, the main jobs performed are:

- operating machinery, tools or equipment for long periods;

- $\quad$ sitting continuously in one position;

- lengthy operation of machines or tools that require skill and dexterity; and

- work requires excessive physical effort.

The jobs that black women do in the light industries require considerable physical effort. This seems be due to the fact that more women are involved in operating machinery in these industries.

The concentration of black women in some jobs could be due to employer discrimination or perception. Although work in the retail sector does not require much physical effort, in manufacturing it requires medium physical strength. Work that requires great physical strength is done to a limited extent in light industries, due mainly to the greater number of women who are machine operators.

\section{Materials handled}

Question 12 of the questionnaire requested respondents to indicate the extent to which black women handle various materials or products. The results are shown in Table 7.

Black women do not handle any materials often in either industry. In retail trade, footwear, textiles, leather products and wearing apparel are frequently handled. Relatively important in retail trade are also paper products, nonmetallic products, plastic products, food, soaps and pottery. In manufacturing, paper products, food and beverages are mostly handled. Women do not handle materials such as motor vehicles and accessories, scientific equipment, metal products, electrical equipment, fertilizers, edible oils and furniture to any significant level. 
Table 7 Materials handled in manufacturing and retail trade

\begin{tabular}{|l|c|c|c|c|c|}
\hline \multirow{2}{*}{ Materials handled } & \multicolumn{2}{|c|}{ Manufacturing } & \multicolumn{2}{c|}{ Retail trade } & \multirow{2}{*}{ P-value } \\
\cline { 2 - 5 } & Mean & Std & Mean & Std & \\
\hline Motor & 1.12 & 0.550 & 1.12 & 0.489 & 0.975 \\
Paper & 1.70 & 1.189 & 1.83 & 1.029 & 0.366 \\
Chemicals & 1.46 & 1.000 & 1.21 & 0.664 & 0.015 \\
Metal products & 1.43 & 0.951 & 1.37 & 0.730 & 0.569 \\
Scientific equipment & 1.44 & 1.001 & 1.06 & 0.275 & 0.000 \\
Electrical & 1.29 & 0.779 & 1.32 & 0.690 & 0.773 \\
Plastic products & 1.40 & 0.940 & 1.93 & 1.078 & 0.000 \\
Non- metallic & 1.30 & 0.845 & 1.68 & 0.913 & 0.000 \\
products & & & & & \\
Fertilizers & 1.05 & 0.378 & 1.10 & 0.375 & 0.337 \\
Edible oils & 1.16 & 0.596 & 1.28 & 0.791 & 0.145 \\
Beverages & 1.59 & 1.088 & 1.56 & 1.042 & 0.812 \\
Food & 1.76 & 1.220 & 1.62 & 1.115 & 0.333 \\
Furniture & 1.22 & 0.675 & 1.49 & 0.927 & 0.008 \\
Soaps & 1.39 & 0.910 & 1.78 & 1.077 & 0.001 \\
Textiles & 1.38 & 0.967 & 2.52 & 1.329 & 0.000 \\
Pottery & 1.23 & 0.778 & 1.68 & 0.985 & 0.000 \\
Candles & 1.07 & 0.431 & 1.53 & 0.935 & 0.000 \\
Wearing apparel & 1.34 & 0.902 & 2.23 & 1.431 & 0.000 \\
Leather products & 1.29 & 0.787 & 2.60 & 1.452 & 0.000 \\
Footwear & 1.26 & 0.824 & 2.63 & 1.460 & 0.000 \\
\hline
\end{tabular}

Black women mostly handle non-durable goods (beverages and food) and semidurable goods (clothing and footwear) rather than durable goods (cars and furniture). Also, the market value of the output they handle is low which would have a direct bearing on wage levels and conditions of employment.

The type of products and materials handled by black women indicates that they are concentrated in the traditional fermale industries of manufacturing, such as textile, food and beverages. Even in retail trade, black women are responsible for output that does not have high monetary value.

\section{Importance of special skills}

Question 14 of the questionnaire required the respondent to indicate the importance of certain skills for job performance; see Figure 3. 
Figure 3 Importance of special skills for job performance in manufacturing and retail industries

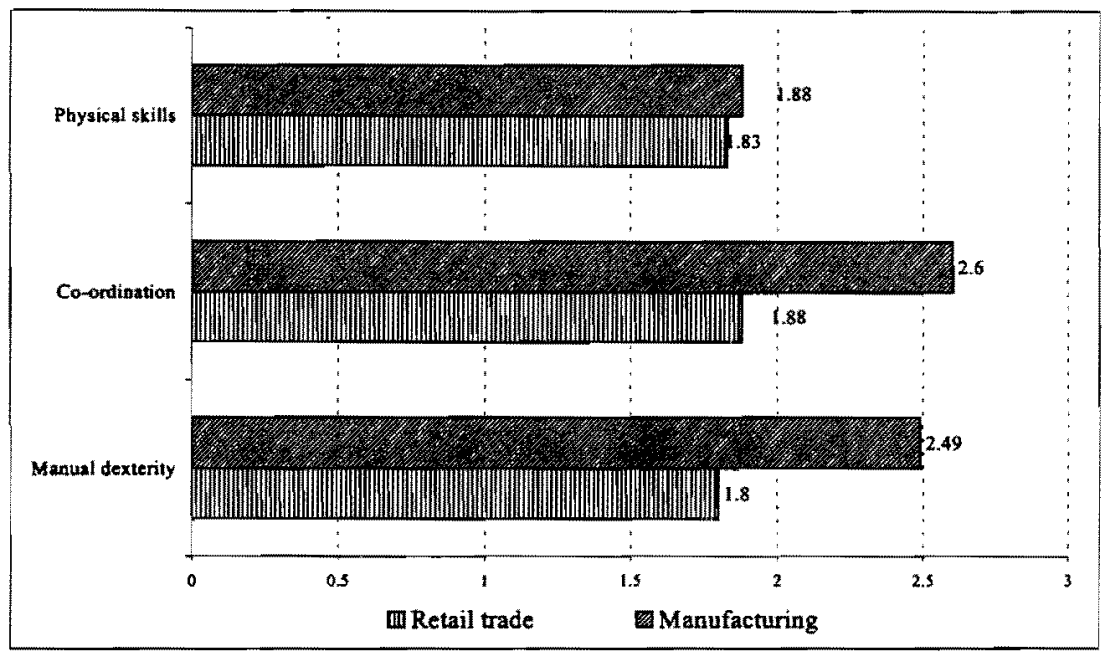

This section attempted to determine whether black women workers required any special skills to do their jobs. The skills concerned are: manual dexterity, coordination and physical skills. None of the skills seem to be especially needed in the retail industry. Eye-hand co-ordination and manual dexterity skills are significantly more important in manufacturing. Physical skills (means score of 1.8) are deemed unnecessary in both industries. Comparing light and heavy industries, all three skills are relatively more important in light compared to heavy industries due to the greater number of women machine operators. The overall impression gained is that job-specific skills are unnecessary and that workers are interchangeable between jobs.

\section{Representation in different skill categories}

Question 21 of the questionnaire aimed to determine the skill levels of workers. Figure 4 displays the scores obtained. 


\section{Figure 4 Skills levels of black women in manufacturing and retail trade}

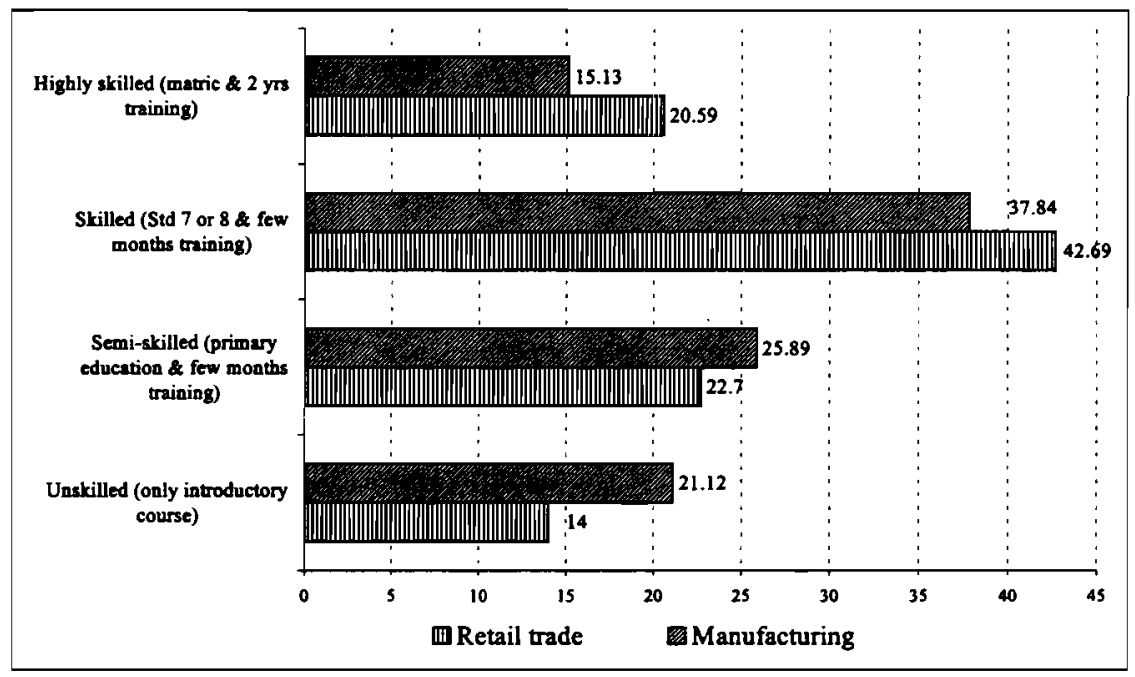

For all firms, $40 \%$ of black women workers were skilled and $24 \%$ semi-skilled. In both retail trade $(42.69 \%)$ and manufacturing $(37.84 \%)$ industries, the majority or workers were classified as skilled - that is, they had a standard 7 or standard 8 education. The second highest group was semi-skilled workers, $22.7 \%$ in retailing and $25.89 \%$ in manufacturing. The percentage of highly skilled was comparatively low, $20.59 \%$ in retail and $15.13 \%$ in manufacturing. The number of unskilled black women workers was much higher in manufacturing (21.12\%) compared to retail (14\%). Even though one-fifth of the black women in retailing and more than $10 \%$ of those in manufacturing were highly skilled, they did not perform work commensurate with their skill levels. Two possible explanations are plausible. On the one hand, it could be that their skills were undervalued. On the other hand, maybe these women accepted any job owing to the limited number of job vacancies.

The number of highly skilled black women is likely to increase in future, given the greater accessibility to education and training opportunities.

\section{Representation in different departments}

In question 19, the percentage of black women in the different departments was asked for. Table 8 shows the results obtained. 
Table 8 Percentage black women per department in manufacturing and retail industries

\begin{tabular}{|l|c|c|c|c|c|}
\hline Representation of black & \multicolumn{2}{|c|}{ Manufacturing } & \multicolumn{2}{|c|}{ Retail trade } & \multirow{2}{*}{ P-value } \\
\cline { 2 - 6 } women in the different & Mean & Std & Mean & Std & \\
\hline Factory & 27.16 & 31.919 & 0.800 & 4.134 & 0.0001 \\
Production & 12.30 & 24.407 & 0.360 & 1.815 & 0.0001 \\
Administration & 11.29 & 15.652 & 14.984 & 15.544 & 0.0579 \\
Sales & 3.99 & 10.953 & 51.192 & 29.174 & 0.0001 \\
Clerical & 8.88 & 13.811 & 6.384 & 11.989 & 0.1189 \\
Accounts & 5.20 & 11.166 & 3.648 & 7.835 & 0.1911 \\
Supervisory & 2.94 & 5.922 & 2.824 & 7.458 & 0.8826 \\
Cleaning \& maintenance & 18.66 & 28.238 & 14.600 & 19.609 & 0.1761 \\
Technical & 2.02 & 6.714 & 0.360 & 1.272 & 0.0052 \\
Labourer \& unskilled & 7.50 & 16.876 & 4.848 & 13.130 & 0.1563 \\
\hline
\end{tabular}

In both industries, black women dominated the following four departments or sections:

- $\quad$ sales $(26 \%)$;

- cleaning and maintenance $(17 \%)$;

- factory work $(15 \%)$; and

- administration (13\%).

A mere $1 \%$ of black women were employed in technical jobs and only $2 \%$ in supervisory positions. The number in production and clerical work is approximately $7 \%$ to $8 \%$.

In manufacturing, black women were found in the following departments:

- factory $(27.16 \%)$;

- production $(12.30 \%)$;

- $\quad$ administration (11.29\%); and

- cleaning and maintenance (18.66\%).

In retail trade, the number of black women worked mainly in the following sections:

- $\quad$ administration (14.98\%);

- $\quad$ sales $(51.19 \%)$; and

- cleaning and maintenance ( $14.60 \%)$.

The number of skilled black women is higher in manufacturing than retail trade. But in both industries, the number of black women in supervisory positions is low $(3 \%)$. Also, the number of women in the technical field is low $(2 \%)$. 
In light industry more black women were found in the factory and in heavy industry, in the cleaning and maintenance departments. In heavy industry, factory, production and administration are rated high. The number of black unskilled workers was higher in light industries compared to heavy industries.

The above analysis points to the fact that black women performed mostly secondary kind jobs in most industries. Black women were also concentrated in a limited range of jobs. Furthermore, these jobs are stereotyped and an extension of the household care that women provide at home.

\section{CONCLUSION}

The questionnaire generated information on a number of important issues. The results of the survey confirm the hypothesis that black women are doing work that is rudimentary, quite dangerous, physically demanding and repetitive in nature. In other words, they do mainly semi-skilled work. Most importantly, they work in secondary jobs under both unpleasant and dangerous working conditions (e.g. exposure to dirt, noise, and a high risk of incurring cuts). Black women also perform basic administrative jobs (telephonist, clerk) and genderstereotyped jobs (salesworker, cleaner, serving tea). The jobs of black women are often physically quite demanding as the work involves standing and walking about, lifting goods that weigh an average of $9.5 \mathrm{kgs}$, and doing a large amount of packing in both retail and manufacturing industries. The number black women doing the preferred or primary kind of jobs, such as the technical and supervisory work, is negligible. Even the number of black women doing more challenging jobs, such as bookkeeping and accounts, is low. The labour market thus appears to be segmented along racial and gender lines.

The distribution of black women workers is such that they are found mainly in the factory $(15 \%)$, administration $(13 \%)$, sales $(26 \%)$ and cleaning and maintenance $(17 \%)$. The number of back women in supervisory and technical positions is negligible, namely, $2 \%$ and $3 \%$ respectively.

The nature of jobs that black women perform implies that they constitute a peripheral rather than a core workforce and their activities are subsidiary to the production process. The type of work black women do is prone to rationalization, thereby making women more expendable in the event of downsizing. It is only in the traditional female industries, for example, the textile and food industry, that black women function as machine and general operators and can be viewed as directly responsible for production. 
Deskilling makes workers more interchangeable and expendable. Typically "women's jobs" are more prone to deskilling and displacement from technological change. Microelectronic technology can replace clerical work and repetitive tasks in manufacturing like assembly-line work and packing.

Women in manual work are under-represented in all skilled work, with the exception of machine operators in the light industries, whilst they are again over-represented in jobs like packing. In non-manual work, they are overrepresented in clerical, sales and service jobs.

Black women have been only able to secure employment in almost only low status, menial and low-paying jobs, seeing that racism, classicism and sexism are locked together to limit their employability in the formal labour market. Black women experienced much hardship in their personal and working lives as a result of apartheid. Their marginality in the labour market is evident in the kind of jobs they undertake. Given the transformation of South African society, a growing economy and greater access to education and training, it is hoped that black women workers will rise to the upper levels of the occupational hierarchy. Thus a higher overall material well-being could be attained.

\section{ENDNOTE}

1 A copy of the questionnaire may be obtained from the authors on request.

\section{REFERENCES}

1 BOZZOLI, B. (1983) "Marxism, Feminism and South African Studies", Joumal of Southern African Studies, 9(2): 139-71.

2 BUDLENDER, D. (1991) Women and the Economy, Case Offices: Johannesburg.

3 BERGER, 1. (1992) Threads of Solidarity - Women in South African Industry 1900 - 1980, Indiana University Press: Indianapolis.

4 GWAGWA, N.N. (1989) "The Family and Woman's Emancipation in South Africa", Unpublished paper, Malibongwe Conference: Amsterdam.

5 HAYS, W.L. (1963) Statistics, Holt, Rinehart and Winston: New York.

6 KRAAK, G. (1993) Breaking the Chains - Labour in South Africa in the 1970 s and 1980s, Pluto Press: London.

7 STANDING, G.; SENDER, J. and WEEKS, J. (1996) Restructuring the South African Labour Market - The South African Challenge, International Labour Office: Geneva. 
8 STATISTICS SOUTH AFRICA (1998) Census in Brief, Report no. 1:03:01:11. Pretoria.

9 THEMBA, A. (1986) "Educational Obstacles to Black Advancement", in Black Advancement, Smollan, R. (ed.) Macmillan Press: Johannesburg.

10 WALKER, C. (1990) Women and Gender in Southern Africa to 1945, David Philip: Cape Town.

11 WINER, B.J. (1971) Statistical Principles in Experimental Design, McGraw-Hill Publishers: Tokyo. 